\title{
Toxoplasmosis Sero-Prevalence, Awareness and Risk Behavior Among Pregnant Women Following Antenatal Care in Asella Teaching and Referral Hospital, Asella, Ethiopia
}

\author{
Shimeles Adugna Elemo \\ Medical Laboratory Sciences Department, Collage of Health Sciences, Arsi University, Asella, Ethiopia
}

Email address:

Shimeadu39@gmail.com

\section{To cite this article:}

Shimeles Adugna Elemo. Toxoplasmosis Sero-Prevalence, Awareness and Risk Behavior Among Pregnant Women Following Antenatal Care in Asella Teaching and Referral Hospital, Asella, Ethiopia. International Journal of Biomedical Science and Engineering.

Vol. 8, No. 3, 2020, pp. 28-35. doi: 10.11648/j.ijbse.20200803.12

Received: August 21, 2020; Accepted: September 3, 2020; Published: September 19, 2020

\begin{abstract}
Toxoplasmosis is caused by infection with the protozoan Toxoplasma gondii (T. gondii), an obligate intracellular parasite. The infections produced a wide range of clinical syndromes in humans, land and sea mammals, and various bird species. Toxoplasmosis is especially important among Immune-compromised patients and pregnant women. Infection of mothers during pregnancy by Toxoplasma gondii may have serious consequences for fetus ranging from miscarriage, central nervous system involvement, retinochoroditis, or at birth subclinical infection. Objectives: To determine Toxoplasmosis seroprevalence, awareness and risk Behavior among pregnant women following antenatal care in Asella Teaching and Referral Hospital, Asella, Ethiopia. Methods: Institutional based quantitative cross sectional study design was conducted on sample size of 384 from December 1, 2018 to June 30, 2019. To collect the demographic and risk factor related data a pre-tested Structured, questionnaire was used. Serum sample, collected was tested for Toxoplasma Immunoglobulin G (IgG) and Toxoplasma Immunoglobulin M (IgM) antibodies using anti- IgG and IgM antibodies by Toxoplasma immune-chromatographic test (ICT) IgG-IgM test. To show association between the dependent and independent variables a bivariable and multivariable logistic regression model was applied allowing for p, 0.05 and the confidence interval 95\%. Result: The overall sero- prevalence of T. gondii in the study area was $81.8 \%$. Three hundred and fourteen $(81.8 \%)$ of the pregnant women were IgG seropositive, fifty women $(13 \%)$ were IgM seropositive. fifty women were positive for both IgG and IgM. None of the pregnant women were positive exclusively for $\mathrm{IgG}$ and $\mathrm{IgM}$ ani-bodies. eating raw meat $(\mathrm{COR}=3.480,95 \% \mathrm{CI}: 1.450-8.352 ; \mathrm{P}=0.005, \mathrm{AOR}=3.798$, 95\%CI: 1.249-11.550, $\mathrm{P}=0.19)$, using unpasteurized milk $(\mathrm{COR}=3.860,95 \% \mathrm{CI}: 2.118-7.037 ; \mathrm{P}=0.000, \mathrm{AOR}=3.907,95 \% \mathrm{CI}$ : 1.744-8.751, $\mathrm{P}=0.001)$, having three or more children $(\mathrm{COR}=2.194,95 \% \mathrm{CI}$ : $1.065-4.518 ; \mathrm{P}=0.033)$ and Consumption of raw egg $(\mathrm{COR}=2.042,95 \% \mathrm{CI}$ : 1.049-3.974; $\mathrm{P}=0.036)$. Conclusion: The sero-prevalence of $\mathrm{T}$. gondii antibodies was high among the pregnant women. Those who consumed raw meat and egg, unpasteurized milk and those who have three or more children were at higher risk of T. gondii infection. Hence, blood screening for Toxoplasmosis, health education and awareness creation among pregnant women should be done during antenatal follow up.
\end{abstract}

Keywords: Sero-prevalence, Pregnant Women, Risk Factors. T. gondii, Asella, Ethiopia

\section{Introduction}

Toxoplasmosis is caused by the Toxoplasma gondii ( $T$. gondii), an obligate, intracellular protozoan, which is a widespread zoonotic parasite which can infect all warmblooded animals [1], and is one of the most common zoonosis in the world [2]. Because of the existing high rates of infection between the human populations (expected as 30 $50 \%$ ) it is considered a global health hazard [3]. In Ethiopia the highest prevalence $(95.1 \%)$ was reported from Butajira from patients found in 15-49 age groups [4], 94\% prevalence among HIV/AIDS patients from Tikur Anbessa Specialized Hospital [5], and $85.4 \%$ among pregnant women in Addis 
Ababa [6]. Toxoplasmosis is witnessed by a wide range of clinical conditions. The majority of infections is naturally asymptomatic or causes a slight self-limiting 'flu' like illness. Infection at primary pregnancy can be spread to the fetus and causes hereditary toxoplasmosis and finally resulted in miscarriages, in utero death, delay growth in neonate, ophthalmic and neurological diseases [7-10].

The expected global problem of hereditary toxoplasmosis was 19,000 new cases each year resulting in the loss of about 1.2 million Disability-Adjusted Life Years (DALYs) [11].

Cats and other felines are the final hosts of $T$. gondii and accordingly the lone source of ecologically resistant oocysts in nature. From the major routes of infections for humans some of them are: close interaction with cats or cat excreta ingestion of oocysts, eating of foods or soil polluted with oocysts and drinking of contaminated water with oocysts; ingestions of tissue cysts due handling/consumption raw or undercooked meat of infected animals hosts, transplantation of infected organs, blood transfusion and congenital infection. Drinking of unpasteurized milk from infected animals and eating of raw egg can also transmit this parasite [9, 12-13].

Antenatal screening for $T$. gondii infection is based detection of anti-toxoplasma specific IgM and $\operatorname{IgG}$ is the backbone in controlling the risk of inherited toxoplasmosis. Maternal-fetal intervention can be attained through drugs such as spiramycin which stop congenital toxoplasmosis by more than $60 \%$ [14].

Exposure rates to toxoplasmosis vary greatly to the topographical locality, socioeconomic prominence, traditional and spiritual opinions of a population [15]. Therefore, there is a necessity to determine the prevalence in different locations. Confirmation of zoonotic infection among cats and livestock animals of Ethiopia is the illustrations of the presence of the parasite and hence the potential for human infection [16-18]. Current trends in foods and lifestyle with fast foods substituting traditional cooking and popularity of cohort animals, (especially cats, as they require minimal care) and the plenty of stray cats, could increase the probability of experience to toxoplasmosis.

Prevention of congenital toxoplasmosis depends mainly on avoidance of risk factors during pregnancy. But, uncertainty about how most women acquire infection results in advice to avoid numerous risk factors which makes compliance difficult. Therefore, alertness is required with regard to toxoplasmosis and identification of significant associations between known risk factors and sero-positivity to $T$. gondii among susceptible groups. This will be surely helpful in adopting appropriate prevention and control methods as accommodated for each group. In addition since, only few sero-prevalence among females and neonates have been studied and there is no antenatal screening program for pregnant women for toxoplamosis in Ethiopia and also there is no studies have investigated the sero-prevalence, awareness of toxoplasmosis and related preventive Behaviour patterns among pregnant women in Aris zone, it necessities to have evidence concerning $T$. gondii in Arsi zone.

Therefore, the aim of this study is to determine
Toxoplasmosis sero-prevalence, awareness and risk Behaviour among pregnant women following antenatal care in Asella Teaching and Referral Hospital, Asella, Ethiopia.

\section{Methods and Materials}

\subsection{Study Area and Period}

An institutional based cross-sectional study design was done at Asella Teaching and Referral) Hospitals from December 01, 2018 to February 30, 2019. Asella Teaching and Referral Hospital found in Assela town, Arsi Zone, at 175 kilometers to the east of Addis Ababa, the capital city of Ethiopia.

\subsection{Study Design and Period}

Cross-sectional study design was conducted from December 01, 2018 up to February 30, 2019 to determine the sero-prevalence of toxoplasmosis, awareness and its associated risk factors in Asella Teaching and Referral Hospital.

\subsection{Source and Study Population}

\subsubsection{Source Population}

All pregnant women in Asella referral and teaching Hospital catchment area.

\subsubsection{Study Population}

All pregnant women following antenatal care in Asella referral and teaching Hospital.

\subsection{Eligibility Criteria}

1) Inclusion criteria: A pregnant woman who was come to selected Hospitals for the first time for antenatal care during sample collection period for current pregnancy.

2) Exclusion criteria: Mothers who can't respond because of serious illness and who was come more than once during sample collection period to selected Hospital for antenatal service.

\subsection{Sample Size Determination and Sampling Technique}

\subsubsection{Sample Size Determination}

The sample size was calculated to estimate the prevalence of toxoplasma antibodies in this population. For the calculation, prevalence was assumed to be $50 \%$ because there is no previous research done on this parasite among pregnant women in Arsi zone by bearing in mind a confidence interval of $95 \%$ and the tolerable difference to be $5 \%$, the least required sample size was 384 . The sample was collected by engaging all agreeable pregnant women at their first visit to the antenatal clinic of Asella Teaching and Referral Hospital.

$$
\text { Sample size }=\frac{(\mathrm{Z} \alpha / 2)^{2} \mathrm{p}(1-\mathrm{p})}{\mathrm{d}^{2}}
$$

Where:

P: An estimate of the prevalence rate for the population 
$(\mathrm{P}=50 \%)$

$\mathrm{d}$ : absolute precision $(\mathrm{d}=5 \%=0.05)$

$\mathrm{Z} \alpha / 2$ : The standard normal variable at $95 \%$ confidence level when $\alpha=5 \%$. $(\mathrm{Z} \alpha / 2=1.96)$

$$
\text { So, } \mathrm{n}=\frac{\mathrm{Z} \alpha / 2)^{2} \mathrm{p}(1-\mathrm{p})}{d^{2}}=\frac{2(1.96)^{2} \times 0.5(1-0.5)}{(0.05)^{2}}=384
$$

\subsubsection{Sampling Techniques}

All pregnant women who were come to Asella Teaching and Referral Hospital for the $1^{\text {st }}$ time for antenatal care and willing to participate in the study were included until required sample size was achieved.

\subsection{Data Collection and Analysis Procedures}

\subsubsection{Socio Demographic and Clinical Features}

After clear training was given for five midwifes, five medical laboratory technologists and five facilitators from who were selected from Asella teaching and referral hospitals data collection was started. To collect Socio demographic and clinical features a pretested questionnaire was administered by Midwifes and trained research assistants' information from pregnant women at selected hospitals antenatal care unit was gathered. The questions was produced information on four major areas: (a) socio-demographic information of the participants such as age, ethnicity, level of education, employment status, marital status, area of residence; (b) details of prior adverse birth outcomes, from multigravida i.e. miscarriages, still births, children with delayed milestones; (c) disease-related risk factors such as cat ownership, personal hygiene (frequency of hand washing), kitchen hygiene (frequency of washing utensils, cutting board and knife after preparation of meat), consumption of raw meat, cooking of meat, frequency of consuming unwashed raw vegetables and fruits, frequency of having non-homemade meals and exposure to soil; and finally, (d) the awareness of toxoplasmosis and sources of information. After implementation the questionnaire, each subject will be educated on significance and prophylactic actions against toxoplasmosis using an information sheet.

\subsubsection{Laboratory Tests}

Two milliliters of blood was collected aseptically from each participant into sterile containers and centrifuged in the collected Hospitals and serum was separated by trained laboratory technologist at Arsi University Asella Teaching and Referral Hospital laboratory department. At Arsi University Asella Teaching and Referral Hospital laboratory department, the serum was tested on the day of receipt for $T$. gondii-specific antibodies using a commercial kit (On Site Toxo IgG/IgM Rapid Test-Dip Strip ${ }^{\circledR}$ CTK Biotech. Inc. USA) according to the manufacturer's instructions by two senior laboratory technologists. The participants were made aware of the results of the serological investigations and its interpretation.

\subsubsection{Data Analysis Procedures}

Data generated from questionnaire survey and laboratory investigations was recorded and coded using Microsoft Excel spreadsheet (Microsoft Corporation) and was analyzed using STATA version 13.0 for Windows (Stata Corp. College Station, TX, USA) by researchers. The sero-prevalence was calculated as the number of seropositive samples divided by the total number of samples tested. To identify predictors of sero-positivity, first the association of the potential risk factors (age, gestational age, educational status, contact with cats' feces, presence of domestic cat, way of life of domestic cats, etc) was analyzed by univariable logistic regression. Then all non- collinear variables with $\mathrm{P}$-value $\leq 0.25$ in univariable logistic regression analysis was included in the final multivariable logistic regression model to construct the likely model $(\mathrm{P}<0.05)$. The model will be reduced by backwards elimination of non-significant variables $(P>0.05)$ based on likelihood ratio test to define the model that would best fit the data.

\subsection{Dissemination of Research Finding}

The research findings will be presented to the Arsi University and other stake holders, shared to Arsi Zonal Health Bureau, Regional Health Bureau, Federal Minister of Health (FMOH) and organizations/partners working on human health in the country. Finally effort will be made to publish the findings on peer reviewed scientific journal.

\subsection{Significance and Beneficiary of the Study}

The finding will be significant both for researcher, communities and government in adding information regarding Toxoplasmosis sero-prevalence, awareness, and risk Behaviour among pregnant women following antenatal care in Arsi zone, Ethiopia. Nationally it develops the understanding of relationship between having cat, eating raw meat and vegetables, blood transfusion, organ transplantation, drinking contaminated water, eating soil and so on with congenital toxoplasmosis.

\subsection{Expected Outcome}

A wide range of data based on which rigorous generalizations and recommendations can be made based on the data was obtained from the diversity score survey and laboratory analysis of sample.

\subsection{Quality Assurance}

Strict measures were taken throughout the analytic process. Five percent of the Questionnaire was pre-tested among pregnant women attending at Asella Referral and teaching Hospital (Asella town), and Questionnaire was revised accordingly. Data collectors were trained for 3 days on how to con duct the interview and the sampling process. Completed questionnaires were reviewed immediately to ensure accuracy and legibility. Quality control samples were tested parallel with the research samples and standard operating procedures were followed during the laboratory investigation. 


\section{Results}

\subsection{Socio-demographic Characteristics}

A total of 384 pregnant women with a reply rate of $100 \%$ of which majority $(65 \%)$ of them were urban dwellers and the mean age $( \pm \mathrm{SD})$ of the study subjects were $26.2( \pm 6.55)$ years were included in the study. The majority $(51 \%)$ of the study members were found within the age cluster of 15-24.9 years. Nearly all $(98.2 \%)$ of the study members were not have any information about Toxoplasmosis and its mode of transmission (Table 1).

Table 1. Sero-prevalence of Toxoplasma gondii antibody and the associated risk factors among pregnant women ( $n=384$ ), Asella, Ethiopia 2019.

\begin{tabular}{|c|c|c|c|c|c|c|c|}
\hline & Total n (\%) & Negative n $(\%)$ & Positive n (\%) & P-Value & COR 95\%(CI) & P-Value & AOR 95\%(CI) \\
\hline \multicolumn{8}{|l|}{ Age group (in Years) } \\
\hline $15-24.9$ & $196(51 \%)$ & $35(50 \%)$ & $161(51.2 \%)$ & .943 & 1 & .736 & 1 \\
\hline $26-24.9$ & $174(45.3 \%)$ & $32(45.7 \%)$ & $142(45.2 \%)$ & .738 & $1.255(.332-4.734)$ & .658 & $0.551(.039-7.704)$ \\
\hline $35+$ & $14(3.6 \%)$ & $3(4.3 \%)$ & $11(3.5 \%)$ & .779 & $1.210(.319-4.590)$ & .553 & $0.457(.034-6.076)$ \\
\hline \multicolumn{8}{|l|}{ Educational Status } \\
\hline Illiterate & $29(7.6 \%)$ & $5(7.1 \%)$ & $24(7.6 \%)$ & .723 & 1 & .470 & 1 \\
\hline Complete elementary school & $46(12 \%)$ & $4(5.7 \%)$ & $42(13.4 \%)$ & .602 & $1.232(.562-2.701)$ & .274 & $1.67(.667-4.182)$ \\
\hline Incomplete high school & $30(7.8 \%)$ & $6(8.6 \%)$ & $24(7.6 \%)$ & .167 & $.424(.126-1.432)$ & .319 & $0.496(.125-1.970)$ \\
\hline Complete high school & $73(19 \%)$ & $13(18.6 \%)$ & $60(19.1 \%)$ & .849 & $1.114(.368-3.373)$ & .565 & $1.476(.392-5.558)$ \\
\hline Incomplete higher education & $26(6.8 \%)$ & $5(7.1 \%)$ & $21(6.7 \%)$ & .938 & $.965(.397-2.344)$ & .329 & $1.668(.598-4.656)$ \\
\hline Complete higher education & $60(15.6 \%)$ & $11(15.7 \%)$ & $49(15.6 \%)$ & .922 & $1.061(.328-3.432)$ & .673 & $1.348(.337-5.390)$ \\
\hline \multicolumn{8}{|l|}{ Trimesters } \\
\hline First (<14weeks) & $77(20.1 \%)$ & $8(11.4 \%)$ & $69(22 \%)$ & .068 & 1 & .124 & 1 \\
\hline Third ( $>28$ weeks) & $157(40.9 \%)$ & $36(51.4 \%)$ & $157(40.9 \%)$ & .223 & $0.705(.401-1.238)$ & .879 & $1.055(.531-2.093)$ \\
\hline \multicolumn{8}{|l|}{ Information About Toxoplasmosis } \\
\hline Yes & $7(1.8 \%)$ & $1(1.4 \%)$ & $6(1.9 \%)$ & & 1 & & 1 \\
\hline No & $377(98.2 \%)$ & $69(98.6 \%)$ & $308(98.1 \%)$ & .786 & $.744(.088-6.279)$ & .789 & $.713(.059-8.546)$ \\
\hline \multicolumn{8}{|l|}{ Number of children } \\
\hline$<$ or $=$ one & $150(39.1 \%)$ & $31(44.3 \%)$ & $119(37.9 \%)$ & .075 & 1 & .063 & 1 \\
\hline two & $115(29.9 \%)$ & $13(18.6 \%)$ & $102(32.5 \%)$ & .814 & $1.073(.596-1.931)$ & .764 & $.891(.420-1.891)$ \\
\hline three and above & $74(19.3 \%)$ & $16(22.9 \%)$ & $58(18.5 \%)$ & .033 & $2.194(1.065-4.518)^{*}$ & .034 & $.389(.163-.931)^{*}$ \\
\hline \multicolumn{8}{|l|}{ History of abortion } \\
\hline Yes & $119(31 \%)$ & $100(31.8 \%)$ & $19(27.1 \%)$ & .442 & $.797(.447-1.421)$ & .240 & $.669(.342-1.308)$ \\
\hline No & $265(69 \%)$ & $214(68.2 \%)$ & $51(72.9 \%)$ & & 1 & & 1 \\
\hline \multicolumn{8}{|l|}{ History of contact with cat's feces } \\
\hline Yes & $375(97.7 \%)$ & $67(95.7 \%)$ & $308(98.1 \%)$ & .248 & $.435(.106-1.784$ & .078 & $.203(.342-1.308)$ \\
\hline Yes & $302(78.6 \%)$ & $59(84.3 \%)$ & $243(77.4 \%)$ & .206 & $1.567(.781-3.143)$ & .953 & $.971(.361-2.609)$ \\
\hline No & $82(21.4 \%)$ & $11(15.7 \%)$ & $71(22.6 \%)$ & & 1 & & 1 \\
\hline \multicolumn{8}{|c|}{ Consumption of raw fruit and vegetable } \\
\hline Yes & $359(93.5 \%)$ & $65(92.9 \%)$ & $294(93.6 \%)$ & .813 & $0.884(.320-2.443)$ & .089 & $.285(.067-1.209)$ \\
\hline No & $25(6.5 \%)$ & $5(7.1 \%)$ & $20(6.4 \%)$ & & 1 & & 1 \\
\hline \multicolumn{8}{|l|}{ Consumption of raw meat } \\
\hline Yes & $301(78.4 \%)$ & $64(91.4 \%)$ & $237(75.5 \%)$ & .005 & $3.480(1.450-8.352)^{*}$ & .019 & $3.798(1.249-11.550)^{*}$ \\
\hline No & $83(21.6 \%)$ & $6(8.6 \%)$ & $77(24.5 \%)$ & & 1 & & 1 \\
\hline \multicolumn{8}{|c|}{ Consumption of undercooked raw meat } \\
\hline Yes & $361(94.0 \%)$ & $67(95.7 \%)$ & $294(93.6 \%)$ & .509 & $1.519(.439-5.261)$ & .812 & $1.227(.227-6.623)$ \\
\hline No & $23(6 \%)$ & $3(4.3 \%)$ & $20(6.4 \%)$ & & & & 1 \\
\hline \multicolumn{8}{|c|}{ Consumption of unpasteurized milk } \\
\hline Yes & $200(52.1 \%)$ & $54(77.1 \%)$ & $146(46.5 \%)$ & .000 & $3.860(2.118-7.037)^{*}$ & .001 & $3.907(1.744-8.751)^{*}$ \\
\hline No & $184(47.9 \%)$ & $16(22.9 \%)$ & $168(53.5 \%)$ & & 1 & & 1 \\
\hline \multicolumn{8}{|l|}{ Consumption of raw egg } \\
\hline Yes & $52(13.5 \%)$ & $15(21.4 \%)$ & $37(11.8 \%)$ & .036 & $2.042(1.049-3.974)^{*}$ & .122 & $1.921(.840-4.391)$ \\
\hline No & $332(86.5 \%)$ & $55(78.6 \%)$ & $277(88.2 \%)$ & & 1 & & 1 \\
\hline \multicolumn{8}{|c|}{ Blood donated or organ transplanted before } \\
\hline Yes & $18(4.7 \%)$ & $5(7.1 \%)$ & $13(4.1 \%)$ & .288 & $1.781(0.614-5.170)$ & & $1.114(.318-3.904)$ \\
\hline No & $366(95.3 \%)$ & $65(62.9 \%)$ & $301(95.9 \%)$ & & & & \\
\hline
\end{tabular}




\begin{tabular}{llllllll}
\hline & Total n (\%) & Negative n (\%) & Positive n (\%) & P-Value & COR 95\%(CI) & P-Value & AOR 95\%(CI) \\
\hline $\begin{array}{l}\text { Type of water for drinking } \\
\text { public supply filtered }\end{array}$ & $271(70.6 \%)$ & $60(85.7 \%)$ & $211(67.2 \%)$ & .060 & 1 & & \\
public supply unfiltered & $85(22.1 \%)$ & $7(10 \%)$ & $78(24.8 \%)$ & .523 & $1.991(.240-16.498)$ & .902 & $0.865(086-8.686)$ \\
well water filtered & $14(3.6 \%)$ & $1(1.4 \%)$ & $13(4.1 \%)$ & .683 & $0.628(.067-5.862)$ & .345 & $0.313(0.028-3.493)$ \\
well water unfiltered & $6(1.6 \%)$ & $1(1.4 \%)$ & $5(1.6 \%)$ & .678 & $0.538(.029-9.985)$ & .553 & $0.393(0.018-8.571)$ \\
Bottled mineral water & $8(2.1 \%)$ & $1(1.4 \%)$ & $7(2.2 \%)$ & .826 & $1.400(0.07-28.120)$ & .854 & $.738(0.029-18.873)$ \\
Presence of rat at home & & & & & & & \\
Yes & $276(71.9 \%)$ & $51(72.9 \%)$ & $225(71.7 \%)$ & .840 & $1.062(.594-1.899)$ & .856 & $.937(.463-1.895)$ \\
No & $108(28.1 \%)$ & $19(27.1 \%)$ & $89(28.3 \%)$ & & 1 & & 1 \\
\hline
\end{tabular}

*=statistically significant at p, 0.05, COR: Crude Odds Ratio, AOR: Adjusted Odds Ratio, CI: Confidence Interval, n=number.

\subsection{Sero-prevalence and Risk Factors for Toxoplasmosis}

The serum sample was collected from 384 gravid women for the serological examination out of these, 314 (81.8\%) were found to be positive for anti-bodies specific to T. gondii. Furthermore, $264(68.8 \%)$ were found to be positive only for IgG; the rest $50(13 \%)$ were positive both for IgM and $\operatorname{IgG}$ (Table 2).

Table 2. IgG sero-prevalence status of study Participant *IgM sero-prevalence status of study Participant Cross tabulation (n=384), Asella, Ethiopia 2019.

\begin{tabular}{|c|c|c|c|c|c|}
\hline & & & \multicolumn{2}{|c|}{ IgM sero-prevalence status of study Participant } & \multirow{2}{*}{ Total } \\
\hline & & & positive & negative & \\
\hline \multirow{4}{*}{ IgG sero-prevalence status of study Participant } & \multirow{2}{*}{ positive } & Count & 50 & 264 & 314 \\
\hline & & $\%$ of Total & $13.0 \%$ & $68.8 \%$ & $81.8 \%$ \\
\hline & \multirow{2}{*}{ negative } & Count & 0 & 70 & \\
\hline & & $\%$ of Total & $0.0 \%$ & $18.2 \%$ & $18.2 \%$ \\
\hline \multirow{2}{*}{ Total } & & Count & 50 & 334 & 384 \\
\hline & & $\%$ of Total & $13.0 \%$ & $87.0 \%$ & $100.0 \%$ \\
\hline
\end{tabular}

Out of the 50 women with recent infection, 10 were in the first trimester, 22 were in the second trimester and only 18 mothers were in the third trimester of pregnancy (Table 3).

Table 3. Respondent's Gestational age * IgM sero-prevalence status of study Participant (n=384), Asella, Ethiopia 2019.

\begin{tabular}{|c|c|c|c|c|c|}
\hline & & & \multicolumn{2}{|c|}{ IgM sero-prevalence status of study Participant } & \multirow{2}{*}{ Total } \\
\hline & & & positive & negative & \\
\hline \multirow{6}{*}{ Respondent's Gestational age } & \multirow{2}{*}{ first trimester } & Count & 10 & 67 & 77 \\
\hline & & $\%$ of Total & $2.6 \%$ & $17.4 \%$ & $20.1 \%$ \\
\hline & \multirow{2}{*}{ second trimester } & Count & 22 & 128 & 150 \\
\hline & & $\%$ of Total & $5.7 \%$ & $33.3 \%$ & $39.1 \%$ \\
\hline & \multirow{2}{*}{ third trimester } & Count & 18 & 139 & 157 \\
\hline & & $\%$ of Total & $4.7 \%$ & $36.2 \%$ & $40.9 \%$ \\
\hline Total & & $\%$ of Total & $13.0 \%$ & $87.0 \%$ & $100.0 \%$ \\
\hline
\end{tabular}

According to the bivariate and multivariate logistic regression analysis, 21 variables including: age, educational level, trimester of pregnancy, source of drinking water, presence of rat at home, contact with cat's feces, consumption of raw: egg, milk, meat, undercooked meat, undercooked embedded meat, and fruit and vegetable / fruit and vegetables without adequate hygiene, Gestational age, blood donated or organ transplanted before, contact with soil without glove, abortion history, number of prenatal care appointments, number of pregnancies information about toxoplasmosis were included. From these risk factors for Toxoplasmosis eating raw meat $\quad(\mathrm{OR}=3.480, \quad 95 \% \mathrm{CI}: \quad 1.450-8.352 ; \quad \mathrm{p}$-value $=0.005$, $\mathrm{AOR}=3.798, \quad 95 \% \mathrm{CI}: \quad 1.249-11.550, \quad \mathrm{p}$-value $=0.19$ ), using unpasteurized milk $(\mathrm{OR}=3.860,95 \% \mathrm{CI}$ : 2.118-7.037; pvalue $=0.000, \quad \mathrm{AOR}=3.907, \quad 95 \% \mathrm{CI}: \quad 1.744-8.751, \quad \mathrm{p}-$ value $=0.001)$, having three or more children $(\mathrm{OR}=2.194$, 95\%CI: 1.065-4.518; $\mathrm{p}$-value $=0.033$ ) and Consumption of raw egg $(\mathrm{OR}=2.042,95 \% \mathrm{CI}: 1.049-3.974 ; \mathrm{p}$-value $=0.036)$ were indicated substantial association with anti-Toxoplasma antibody sero- positivity of the pregnant women (Table 1).

\section{Discussion}

Previously there wasn't known any information about the sero-prevalence of $T$. gondii in Arsi zone and this is the first report of $T$. gondii infection in Asella, Ethiopia. The seroprevalence of $T$. gondii among pregnant women in the study area was found to be $81.8 \%$ (Table 2). This discovery is larger than the findings from Arba minch, Ethiopia 79.3\% [19], Brazil 68.6\% [20], Ghana 51.2\% [21], Tanz ania 30.9\% [22], Sri L anka 29.9\% [23], China 16.8\% [24], and Mexico $10.8 \%$ [25]. The present discovery is similarly higher than the sero-prevalence of $T$. gondii in the lower altitude and higher humidly cities of Kenya: Kisumu (52\%) and 
Mombasa (57\%) [26]. But silt lower than Bench Maji Ethiopia 85.3\% [27] and Addis Ababa 85.4\% [28].

Amongst the sero-positive females, the majority of them were found to have a chronic or past infection. But, fifty women $(50 / 314,16 \%)$ or $13 \%$ of the 384 women was found to have a recent infection (Table 2) which is higher than the studies conducted in Arba Minch Hospital 9 (3.9\%) and Mizan Aman General Hospital 7 (3.0\%) in Ethiopia [19, 27]. Bearing in mind the asymptomatic nature of the disease and the opportunity of congenital spread, the serologic finding of this study should not be overlooked. This is because the health -care facilities in the study area lack specific tests for $T$ gondii and diagnosis isn't completely made which may result in misdiagnosis or delayed diagnosis.

In this study, there were 21 different risk factors have been also evaluated for the sero- prevalence of $T$. gondii but only: eating raw meat, drinking unpasteurized milk, eating raw egg and having three or more children (Table 1) were showed significant association. This discovery is consistent with the studies conducted in Tanzania [22], Mali [29] and have of south of Iran [30].

In these discoveries, contact with garden soil, owing to a domestic cat or presence of rat at home, and consumption of raw vegetables, inadequate washing of fruits and vegetables, educational status, contact with cat's feces and soil without gloves weren't showed significantly associated with $T$. gondii infection (Table 1) which contradicted earlier studies conducted in Ethiopia [19, 27, 30], China [32] and Brazil [33]. This inconsistency might be due to the dissimilarities in socioeconomic status, personal hygiene practices, feeding habits, differences in testing methods, variation immune status of the study members and sample size of each study.

Cats and dogs are supposed to be the vital amps of contamination of T. gondii [34]. In the Ethiopian situation, it is common to see household cats live and sleep to get her with human beings. Cats can directly contaminate humans, other animals, and their neighboring through their feces [35]. Likewise, after contact with cat's feces, dogs can pay to the spread of the organism through mechanical contamination of garden soil, vegetables, and human beings. Therefore, human beings can perhaps get the infection or swallow the oocyst of the parasite through their contaminated hands after direct contact with cats or dogs, garden soil, and surfaces or ingesting of polluted vegetables. Oocysts of $T$. gondii are hard free living phases of the parasite, and consequently are a key contributor to infections related with the abovementioned risk factors [34]. Since they on the other hand, cats or dogs may get the contagion from other warm blooded animals through carnivore contamination, and in sequence infect human creatures [36].

This study was showed as the difference in educational status of the study participants have no effect on the seroprevalence, because only $1.8 \%$ was heard about Toxoplasmosis even though they were in different educational level and $98.2 \%$ doesn't have any information (table 1). This agrees with the study done in Hawassa and
Yirgalem Hospitals southern, Ethiopia which indicated as $99.6 \%$ of the study participants was no information about Toxoplasmosis [37]. But in reality it is extremely important to increase awareness on the transmission of toxoplasmosis at all level.

Even though it weren't showed significant association with Toxoplasmosis in this study, contact with: cat's feces, contaminated soil and water, raw or under cocked fruits and vegetables, gestational age, information about toxoplasmosis, abortion history and presence of rat and domestic cat's it is important to prevent these risk factors as it is evidence by different researches as these were some of the risk factors for Toxoplasmosis [19, 27, 30, 32, 38-41]. But some of current findings agree with research done in northwest Ethiopia which showed as there are no any significant risk factors associated with sero-positivity in relation socio-demographic characters, gestational age, gravidity, consumption of raw vegetable, and blood transfusion $[28,42]$.

\section{Conclusions}

The sero-prevalence of $\mathrm{T}$. gondii antibodies was high among the pregnant women. Those who consumed raw: meat, milk and egg were at higher risk of T. gondii infection. Hence, blood screening for Toxoplasmosis, health education and awareness creation among women of reproductive age group in general and pregnant women in particular should be done during antenatal follow up. It is also alarming to add Toxoplasmosis screening during antenatal checkup. Furthermore, there is prerequisite to control urban stray cat inhabitants to decrease the risk of zoonotic spread of the parasite and further epidemiological studies to determine additional risk factors, economic and health impact of toxoplasmosis are called for.

\section{Abbreviations \\ FMOH Federal Minister of Health \\ ICT Chromatographic test \\ IgG Immunoglobulin $\mathrm{G}$ \\ IgM Immunoglobulin $\mathrm{M}$ \\ PI Principal Investigator \\ RPD Research and publication director}

\section{Declarations}

\section{Ethics Approval and Consent to Participate}

The study was approved by the Ethical Review Committee of the Arsi University Collage of Health Sciences by Ref. No. $2-16 / 09 / 151 / 11$ by date of 12 November 2018 with budget code $\mathrm{COHS} / \mathrm{R} / 0033 / 2018 / 19$. Informed written consent was obtained from the participating pregnant women at the first booking visit. The participants were informed that enrolment to the study was purely voluntary and non-participation was not in any way influence the services provided by the antenatal clinic. 


\section{Consent for Publication}

Not applicable

\section{Availability of Data and Materials}

The data sets used and /or analyzed during the current study are available from the corresponding author or on reasonable request.

\section{Conflict of Interest}

The authors declare that there is no conflict of interests.

\section{Funding}

The source of this research is Arsi University. The fund is used to buy reagents, kits, data collection and diagnosis only.

\section{Authors' Contributions}

SA provided conceptual framework for the project, data collection, guidance for interpretation of the data, perform data analysis, participated in the Parasitological work, performance of statically analysis and guidance for data interpretation. I also read and approved the final manuscript.

\section{Acknowledgements}

I would like to acknowledge Arsi University for fund allocation, Asella referral and teaching hospital laboratory department for serological diagnosis, Mr. Adugna Negussie, Mr. Hailu Fikadu and my wife Sr. Misa Ayele for their unforgettable support from idea sharing, diagnostic kit importing and full support until publication. Finally the study participants for their willingness to participate.

\section{References}

[1] Dubey JP. Toxoplasmosis of animals and humans. Boca Raton, NW: CRC Press; 2010.

[2] Hill DE, Dubey JP. Toxoplasma gondii prevalence in farm animals in the United States. Int Parasitol. 2013; 43: 107-13.

[3] Flegr J, Prandota J, Sovičková M, Israili ZH. Toxoplasmosis-a global threat. Correlation of latent toxoplasmosis with specific disease burden in a set of 88 countries. PLoS One. 2014; 9: 1-22.

[4] Tedla, Y., T. Shibre, O. Ali, G. Tadele, Y. Woldeamanuel, D. Asrat, A. Aseffa, W. Mihret, M. Abebe, A. Alem, A. Habte and G. Medhin, Serum antibodies to Toxoplasma gondii and Herpesvidae family viruses in individuals with schizophrenia and bipolar disorder: a case-control study. Ethiopian Medical Journal, 2011; 49 (3): 211-220.

[5] Aleme, H., G. Tilahun, D. Fekade, N. Berhe and G. Medhin, Sereoprevalence of Immunoglobulin-G and of Immunoglobulin-M Anti Toxoplasma gondii Antibodies in Human Immunodefiiency Virus Infection/Acquired Immunodefiiency Syndrome Patients at Tikur Anbessa Specialized Hospital, Addis Ababa, Ethiopia. Journal of Infectious Disease and Therapy, 2013; 1: 119. doi: 10.4172/2332-0877.1000119.
[6] Gelaye, W., T. Kebede and A. Hailu, 2015. High prevalence of anti-toxoplasma antibodies and absence of Toxoplasma gondi infection risk factors among pregnant women attending routine antenatal care in two Hospitals of Addis Ababa, Ethiopia, International Journal of Infectious Diseases (2015), http://dx.doi.org/10.1016/j.ijid.2015.03.005.

[7] Tenter AM, Heckeroth AR, Weiss LM. Toxoplasma gondii from animals to humans. Int Journal of Parasitol. 2000; 30: $1217-1258$

[8] Holliman RE. Toxoplasmosis. In: Cook GC, Alimuddin Zumla, editors. Mansons tropical diseases, London: Saunders Elsevier; 2009. 1367-73.

[9] Zemene, E., D. Yewhalaw, S. Abera, T. Belay, A. Samuel and A. Zeynudin, Sero-prevalence of Toxoplasma gondii and associated risk factors among pregnant women in Jimma town, Southwestern Ethiopia. BMC Infectious Diseases, 2012; 12 (1): 1.

[10] Kula Jilo and Jemal Adem, Toxoplasmosis and its Current Status in Ethiopia: A Review, Global Veterinaria 17 (2): 135$141,2016$.

[11] Torgerson, PR, Mastroiacovo, P. The global burden of congenital toxoplasmosis: a systematic review. Geneva: Bull. World Health Organization; 2013.

[12] Negash, T., G. Tilahun and G. Medhin, Sero-prevalence of Toxoplasma Gondii in Adama Town, Ethiopia. East African Journal of Public Health, 2008; 5 (3): 211-214.

[13] Skariah, S., M. K. McIntyre and D. G. Mordue, Toxoplasma gondii: determinants of tachyzoite to bradyzoite Conversion. Parasitology Research, 2010; 107 (2): 253-260.

[14] Montoya JG, Remington JS. Management of Toxoplasma gondii infection during pregnancy. Clin Infect Dis. 2008; 47: 554-66.

[15] Singh S, Munawwar A, Rao S, Mehta S, Hazarika NK. Serologic prevalence of Toxoplasma gondii in Indian women of child bearing age and effects of social and environmental factors. PLoS Negl Trop Dis. 2014; 8: 1-9.

[16] Kulasena VA, Rajapakse RP, Dubey JP, Dayawansa PN, Premawansa S. Sero-prevalence of $T$. gondii in cats from Colombo, Sri Lanka. Journal of Parasitology. 2011; 97: 152.

[17] Dubey JP, Rajapakse RP, Ekanayake DK, Sreekumar C, Lehmann T. Isolation and molecular characterization of Toxoplasma gondii from chickens from Sri Lanka. Journal of Parasitol. 2005; 91: 1480-2.

[18] Teshale, S., A. Dumetre, M. L. Dardé, B. Merga and P. Dorchies, Serological survey of caprine toxoplasmosis in Ethiopia: prevalence and risk factors. Parasite, 2007; 14 (2): 155-159.

[19] Yohanes T, Zerdo Z, Chufamo N, Ashenafi Abossie A. Seroprevalence and associated factors of toxoplasma gondii infection among pregnant women attending in antenatal Clinic of Arba Minch Hospital, South Ethiopia: cross sectional study. Transl Biomed. 2017; 8 (1): 105. https://doi.org/10.2167/21720479.1000105 .

[20] Da Silva MG, Vinaud MC, de Castro AM. Prevalence of toxoplasmosis in pregnant women and vertical transmission of toxoplasma gondii in patients from basic units of health from Gurupi, Tocantins, Brazil, from 2012 to 2014. PLoS One. 2015; 10 (11): e0141700. 
[21] Ayi I, Sowah AO, Blay EA, Suzuki T, Ohta N, Ayeh-Kumi PF. Toxoplasma gondii infections among pregnant women, children and HIV-seropositive persons in Accra, Ghana. Trop Med Health. 2016; 44 (1): 17.

[22] Mwambe B, Mshana SE, Kidenya BR, Massinde AN, Mazigo HD, Michael D, Majinge C, Groß U. Sero-prevalence and factors associated with toxoplasma gondii infection among pregnant women attending antenatal care in Mwanza, Tanzania. Parasit Vectors. 2013; 6 (1): 222.

[23] Iddawela et al., Sero-prevalence of toxoplasmosis and risk factors of Toxoplasma gondii infection among pregnant women in Sri Lanka: a cross sectional study. BMC Public Health (2017) 17: 930.

[24] Cong W, Dong XY, Meng QF, Zhou N, Wang XY, Huang SY, Zhu XQ, Qian AD. Toxoplasma gondii infection in pregnant women: a sero-prevalence and case-control study in Eastern China. Biomed Res Int. 2015; 2015.

[25] Alvarado-Esquivel C. del Carmen Terrones-Saldívar M, Hernández-Tinoco J, Muñoz-Terrones MD, GallegosGonzález RO, et al. Seroepidemiology of toxoplasma gondii in pregnant women in Aguascalientes City, Mexico: a crosssectional study. BMJ Open. 2016; 6 (7): e012409.

[26] Nisbet AI, Omuse G, Revathi G, Adam RD. Sero-prevalence data at a private teaching hospital in Kenya: An examination of Toxoplasma gondii, cytomegalovirus, rubella, hepatitis A, and Entamoeba histolytica. PloS one. 2018; 13 (10): e0204867.

[27] Abamecha F, Awel H. Sero-prevalence and risk factors of toxoplasma gondii infection in pregnant women following antenatal care at Mizan Aman general hospital, bench Maji zone (BMZ), Ethiopia. BMC Infect Dis. 2016; 16: 460. https://doi.org/10.1186/s12879-016-1806-6.

[28] W. Gelaye et al., High prevalence of anti-toxoplasma antibodies and absence of Toxoplasma gondii infection risk factors among pregnant women attending routine antenatal care in two Hospitals of Addis Ababa, Ethiopia. International Journal of Infectious Diseases 34 (2015) 41-45.

[29] Ouologuem DT, Djimde AA, Diallo N, Doumbo OK, Roos DS. Toxoplasma gondii sero-prevalence in Mali. Journal of Parasitol. 2013; 99: 371-4.

[30] Khademi et al.: Prevalence and Risk Factors of Toxoplasma gondii Infection among Pregnant Women in Hormozgan Province, South of Iran. Iran Journal of Parasitol: 2019; 14: 167-173.

[31] Zemene E, Yewhalaw D, Abera S, Belay T, Samuel A, Zeynudin A. Sero-prevalence of toxoplasma gondii and associated risk factors among pregnant women in Jimma town, southwestern Ethiopia. BMC Infect Dis. 2012; 12: 337.
[32] Wei Cong et al., Toxoplasma gondii Infection in Pregnant Women: A Sero-prevalence and Case-Control Study in Eastern China. BioMed Research International. Volume 2015, Article ID 170278, 6 pages http://dx.doi.org/10.1155/2015/170278.

[33] Sroka S, Bartelheimer N, Winter A, Heukelbach J, Ariza L, Ribeiro $\mathrm{H}$, et al. Prevalence and risk factors of toxoplasmosis among pregnant women in Fortaleza, northeastern Brazil. Am Journal of Trop Med Hyg. 2010; 83: 528-3.

[34] VanWormer E, Fritz H, Shapiro K, Mazet JA, Conrad PA. Molecules to modeling: toxoplasma gondii oocysts at the human-animal-environment interface. Comp Immunol Microbiol Infect Dis. 2013; 36 (3): 217-31.

[35] Alsammani MA. Sero-epidemiology and risk factors for toxoplasma gondii among pregnant women in Arab and African countries. Journal of Parasit Dis. 2016; 40 (3): 56979 .

[36] Robert-Gangneux F, Dardé ML. Epidemiology of and diagnostic strategies for toxoplasmosis. Clin Microbiol Rev. 2012; 25 (2): 264-96.

[37] Fenat. Sero-prevalence of Toxoplasma gondii among pregnant women attending antenatal clinics at Hawassa University Comprehensive specialized and Yirgalem General Hospitals, in southern Ethiopia. BMC Infectious Diseases.2019; 19: 1050.

[38] Liu Q, Wei F, Gao S, Jiang L, Lian H, Yuan B, et al. Toxoplasma gondii infection in pregnant women in China. Trans R Soc Trop Med Hyg. 2009; 103: 162-6.

[39] Riyadh A. Alzaheb and Osama Al-Amer. The Sero-prevalence and Risk Factors of Toxoplasmosis among Female Undergraduate University Students in Saudi Arabia. Oman Medical Journal [2017], Vol. 32, No. 6: 486-491.

[40] Andiappan et al. Knowledge and practice on Toxoplasma infection in pregnant women from Malaysia, Philippines, and Thailand. Frontiersin Microbiology | Microbial Immunology. June 2014; Vol. 5, Article $291 \mid$ 1-8.

[41] Anubhuti, Radha Rani Roy, J. P. Mittra, Shoukat Jahan Begum. "Sero-prevalence of Toxoplasma Gondii in Spontaneous Abortions in Pregnant Women". Journal of Evolution of Medical and Dental Sciences 2015; Vol. 4, Issue 39, May 14; Page: 6763-6768, DOI: 10.14260/jemds/2015/980.

[42] Kefale Awoke et al., Sero-prevalence and associated risk factors of Toxoplasma gondii infection among pregnant women attending antenatal care at Felege Hiwot Referral Hospital, northwest Ethiopia./Asian Pacific Journal of Tropical Medicine 2015; 8 (7): 549-554. 